\title{
Rule use in character classification: Are serial and parallel processing discrete?*
}

\author{
DAVID A. ROSENBAUM \\ Swarthmore College, Swarthmore, Pennsylvania 19081
}

\begin{abstract}
Contrary to predictions of a stochastic self-terminating search model, choice reaction times were lower for rulebound positive sets than for nonrulebound positive sets when memory set sizes were varied and stimulus probabilities were held constant. The result suggests that rule use and chunking, as opposed to probability alone, facilitate character classification. As a corollary, it is proposed that serial and parallel processing differ in degree rather than in kind. The extent to which the memory set has been chunked is the critical variable affecting Ss' scanning practices.
\end{abstract}

In a character classification experiment, the $S$ learns a list and then decides as quickly as possible whether single items presented later belong in the list. Generally, the time required to make the decision increases monotonically with the length of the list (Sternberg, 1966). This fact suggests that Ss compare the test item with each item in the memorized list in a serial fashion. One of the surprising discoveries made with the character classification procedure is that an equal amount of time is taken to indicate whether an item is a member of the list or not. Intuitively, one would expect judgments of membership to take much less time than judgments of nonmembership, since the memory search would be expected to stop when a positive match is made between a test and list item. But because choice reaction times (CRTs) for judgments of membership and nonmembership are roughly equal and can be represented by curves of equal slope, it seems that judgments are made after an exhaustive search through the memory set (Atkinson, Holmgren, \& Juola, 1969; Briggs \& Blaha, 1969; Sternberg, 1966).

Objections have been raised against the claims that a serial and exhaustive search is used in character classification. The monotonic function predicted by a serial search model has not been obtained in several character classification experiments (Clifton, 1973; Kristofferson, 1972b). Sometimes the serial search model has been invoked only because predictions based on a parallel search model were too difficult to derive (e.g., Snodgrass, 1973). Many experiments using tasks other than character classification have yielded results which only a parallel search model could predict (Egeth, Jonidas, \& Wall, 1972; Leonard, 1961; Morin, Konick, Troxell, \& McPherson, 1965; Neisser, 1963; Neisser, Novick, \& Lazar, 1963; Travers, 1973).

Disagreement has also centered on the idea of exhaustive search. Those opposed to the idea (Falmagne

\footnotetext{
*The author, now at Stanford University, would like to thank Jeff Barckley, Bill Barton, Gary Dell, Helen Sichel, and Jeff Travers for their kind assistance. Requests for reprints should be sent to David A. Rosenbaum, Department of Psychology, Stanford University, Stanford, California 94305.
}

\& Theios, 1969; Theios \& Smith, 1972; Theios, Smith, Haviland, Traupman, \& Moy, 1973) have shown that exhaustive search fails to account for stimulus probability effects on reaction time (Bertelson \& Tisseyre, 1966; Biederman \& Zachary, 1970; Falmagne, 1965; Hawkins, Thomas, \& Drury, 1970; Hyman, 1953; Orenstein, 1970) and sequential effects on reaction time (Bertelson, 1963, 1965; Falmagne, 1965; Leonard, Newman, \& Carpenter, 1969; Remington, 1969; Schvaneveldt \& Chase, 1969). Opponents of the exhaustive search model have proposed that scanning is carried out in a self-terminating manner: all items are stored with their respective positive or negative choice responses; these paired associates are stochastically ordered in memory stacks according to their recency and frequency.

In the present paper, the stochastic self-terminating search model is accepted as a valid description of rudimentary character classification. The purpose of this paper is to qualify the stochastic self-terminating search model for higher-order classification. It is proposed here that probability effects on CRT merely foreshadow the effects of chunking and rulemaking. In line with the well-established literature on organizational vs probabilistic factors in learning (Dallett, 1964; Tulving, 1962, 1966; Wallace \& Calderone, 1969), it is assumed that initially probability plays a vital role in chunk and rule formation, but that once chunks and rules are formed they easily outstretch simple probability effects on CRT. As a corollary to this argument, it is proposed that the difference between serial and parallel processing is graded rather than absolute. The graded difference is held to be dependent on the degree to which the memory set has been chunked. When the memory set has been fully chunked, it can be scanned as a whole and thus in parallel.

According to the stochastic self-terminating search model, the only factor affecting CRT is the stimulus probability effect operating in a variably sized memory set. Other factors such as chunking and rules are presumed to have no influence on the scanning performance of Ss. Three pairs of hypotheses can be 
introduced to test this theory: (1a) If the theory is correct, varying the ruleboundedness of positive sets should have no effect on CRTs when stimulus probabilities are held constant. (1b) Ruleboundedness should have an effect if factors other than probability affect character classification. (2a) According to the stochastic self-terminating search model, if the memory set size is varied while stimulus probabilities are held constant, linear CRT curves like those obtained by Sternberg (1966) should be obtained for rulebound and nonrulebound sets. (2b) If rules affect character classification, then nonrulebound sets should yield linear CRT curves like Sternberg's (1966), while rulebound sets should yield nonlinear CRT curves or linear CRT curves with slopes $\leqslant 0$. (3a) If only probability affects CRT, then, when stimulus probabilities are varied, CRTs should exemplify probability effects for rulebound and nonrulebound sets. ( $3 b$ ) If rules also affect CRT, then nonrulebound sets should yield CRTs reflecting probability, while rulebound sets should yield CRTs independent of probability.

Of these hypotheses, only the first pair has been directly tested. Morin, DeRosa, and Stultz (1967), DeRosa and Morin (1970), and DeRosa and Beckwith (1971) demonstrated that organized sets had significant accelerating effects on CRTs, supporting, therefore, Hypothesis $1 \mathrm{~b}$. The second pair of hypotheses, which constitutes the main research target here, has only been studied indirectly. The third pair of hypotheses has not been investigated. Unfortunately, a test of the third hypothesis pair could not be performed in preparing this paper because of an extreme shortage of funds.

Implicit in Hypothesis $2 b$ is the suggestion that structuring is a critical determinant of the type of processing used by the $S$. If rules and chunking yield nonlinear CRT curves or linear CRT curves with slopes $\leqslant 0$, this could mean that parallel processing is used with structured sets, while serial processing is used with less structured sets. An examination of several studies concerning practice effects on character classification lends support to this idea. Mowbray and Rhoades (1959) showed that CRTs diminished with prolonged practice, though the procedure used in this experiment differed markedly from the kind used in standard character classification tasks. Kristofferson (1972a) used a standard character classification procedure and obtained the same result as Mowbray and Rhoades (1959), though only the intercepts of the CRT function diminished with practice. Later, Kristofferson (1972b) obtained diminished intercepts and slopes for response latencies of well-practiced Ss. Here the experimental design included both complete response consistency, where each item in the stimulus set always required only a positive or only a negative response, and nested positive sets, where each positive set contained all the items contained in smaller positive sets. Although the slopes of Kristofferson's (1972b) CRT curves never equalled zero, they closely approximated flatness in the last 14 days of the 25-day experiment. The importance of this finding is that the effects of prolonged practice on item recognition could be made to simulate the effects of very brief practice on visual search (Neisser, Novick, \& Lazar, 1963; Wattenbarger, 1968): parallel processing could be obtained in both paradigms.

Temporal differences in practice effects for the two tasks may have been attributable to differences in the scanning requirements imposed in each task. In visual search, the memory set size is generally one, while the perceptual set size is one through $\mathrm{n}$. In character classification, the memory set size is generally one through $n$, while the perceptual set size is one. Since the perceptual scanning rate is constant when the memory set size is one and the perceptual set size varies (Egeth, Jonidas, \& Wall, 1972; Neisser, Novick, \& Lazar, 1963), and since the perceptual scanning rate is constant when the memory set size varies and the perceptual set size is one (Wattenbarger \& Pachella, 1972), it is the memory search rate which is affected by variably sized memory sets. By implication, then, memory search rate was probably reduced in Kristofferson's (1972b) study. More to the point, her Ss' memory sets were probably subjected to increasing consolidation and structuring so that the sets could be scanned all at once rather than sequentially.

Long familiarity with sets, therefore, may allow for the set unitization which results in parallel scanning. Apparently, the length of familiarization must be greater than one experimental session, for Sternberg (1966) obtained the same linear CRT function whether he used positive sets 120 times or only once. Kristofferson (1972b) began obtaining fairly flat CRT curves after 11 days of testing. Clifton (1973) found that sibling lists known to Ss for many years were (probably) not scanned sequentially, but name lists learned immediately prior to testing were scanned in a sequential fashion.

In spite of the clear chronological effect implied by these data, however, it is doubtful that time alone is the essential parameter determining Ss' scanning patterns, just as time alone is not the prime factor in memory decay (Reitman, 1971). What is more likely is that the activities of rehearsal, consolidation, grouping, and the like lead to successive chunking of memory materials. When chunking is accomplished, elements of the memory set can be scanned simultaneously as a whole. To test the notion that chunking and not time is the critical variable affecting classification practices, a fourth pair of hypotheses can be introduced for experimental purposes: (4a) If chunking is the critical variable affecting the kind of processing used, then a prechunked or rulebound set should immediately yield CRTs indicative of parallel search. (4b) If time is the critical wariable, then CRTs for all sets, prechunked or not, should be solely dependent on time.

The experiment reported here was designed as a direct test of Hypotheses $2 a$ and $2 b$ and an indirect test of Hypotheses $4 a$ and $4 b$. By comparing the present data 
with Kristofferson's (1972b) data on practice effects, a test could be made of the latter pair of hypotheses.

\section{METHOD}

Design

A 2 by 3 factorial design was used. The factorial dimensions were ruleboundedness and memory set size. The memory set ;izes were two, three, and four. For each memory set size a rulebound (R) and nonrulebound (NR) set were constructed. The sets are listed in Table 1 . $R$ sets are accompanied by their cule formulations, with the sign " $x$ " representing "the multiples of ..."

The items used were the digits one through nine. In sonstructing the list of test items for each positive set, several zonditions were met. Lists had 15 items, 5 of which were nembers and 10 of which were nonmembers of the positive set. The two-to-one ratio of negative-to-positive responses was snforced to counterbalance the moderate bias for positive :esponses typically exhibited by $\mathrm{Ss}$ in character classification tasks. In establishing this ratio, it was assumed that probability iffects would hold for response frequencies. Although the iffects of response frequency on CRTs have not been zonclusively established, response probability effects would be expected to operate, based on the stochastic self-terminating search model and the work of Krueger (1970) and Marcel (1970). Since this area has gone relatively unexplored, however, to predictions were made about positive and negative response ZRTs within or between the $R$ and NR conditions.

An effort was made to equalize stimulus probabilities in the test lists. To prevent systematic elimination of items on the ussumption that each item would be shown only once, single epetitions were allowed. Approximately half the items in each test list were repeated. Some digits were never shown in a given test list.

The orders of test items and choice responses were andomized for each test list. The order of positive sets tested was randomized for each $S$, with the constraint that positive sets of equal size could not adjoin.

\section{Materials}

Numerals measuring $1 \times 1 \frac{114}{4}$ in. were drawn by hand with a Staedtler-Mars pen on white $4 \times 5$ in. cards. The cards were shown individually for $160 \mathrm{msec}$ in a Scientific Prototype two-channel tachistoscope. A Standard Type MST500 nillisecond reaction timer was used to clock CRTs. A S-operated Sound Scriber foot pedal was used to start the reaction timer Ind tachistoscope simultaneously. A telegraph-type response key was provided for each hand of S. Either or both of the keys could stop the reaction timer. A separate light for each key was nounted in the relay panel. Only the light for the key that was rressed first would illuminate.

\section{Subjects}

Eleven male and four female Swarthmore students rolunteered to be Ss. Thirteen of the Ss were right-handed and

Table 1

Positive Sets

\begin{tabular}{lccc}
\hline \multirow{2}{*}{$\begin{array}{c}\text { Zulebound- } \\
\text { edness }\end{array}$} & \multicolumn{3}{c}{ Memory Set Size } \\
\cline { 2 - 4 } & 2 & 3 & 4 \\
\hline NR & 1,7 & $4,7,9$ & $1,5,6,8$ \\
R & 4,8 & $3,6,9$ & $2,4,6,8$ \\
& $(\times 4)$ & $(\times 3)$ & $(\times 2)$ \\
\hline
\end{tabular}

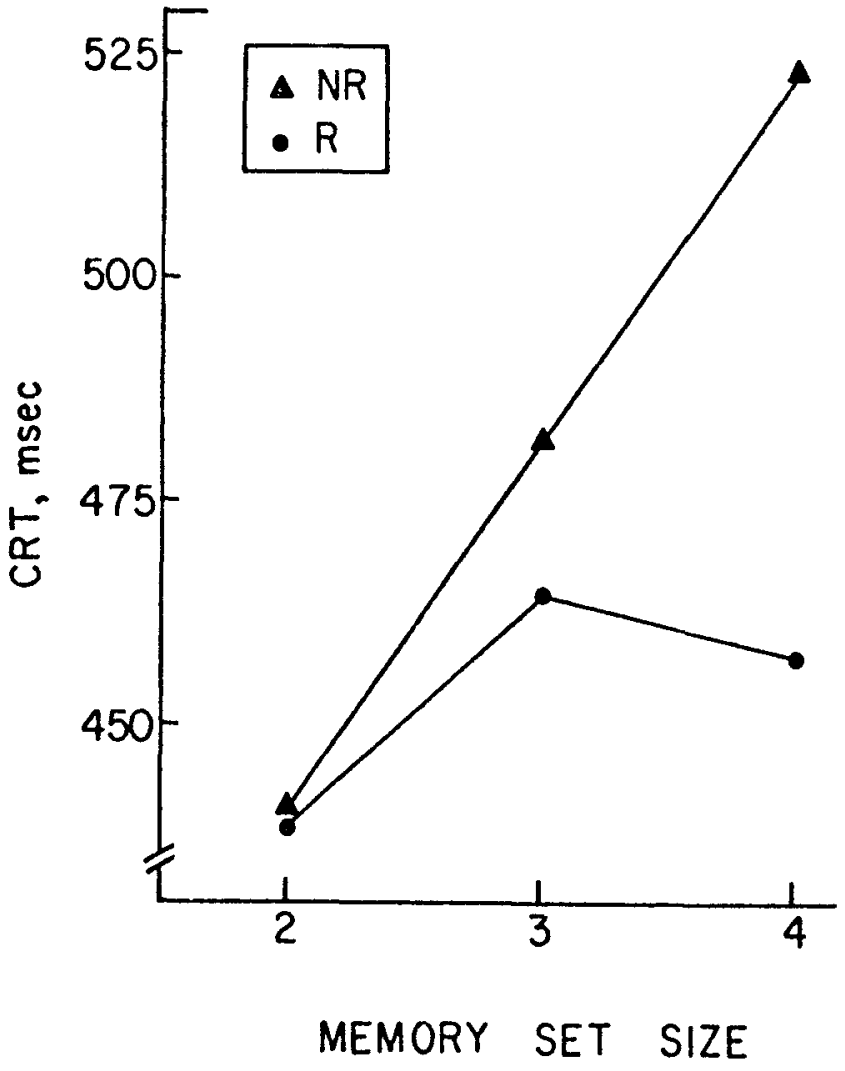

Fig. 1. Mean CRTs in R and NR conditions for each memory set size.

two were left-handed. Ss were paid $\$ 1.60$ for their services in the hour-long experiment.

\section{Procedure}

At the beginning of the experiment Ss were familiarized with the apparatus. So that Ss could learn to coordinate their foot and finger presses, a practice session was included in which Ss responded 10 times with the right and left index finger to a self-started homogeneous flash. Reaction times were recorded by E during this exercise.

Next, Ss were told that they would hear lists drawn from the digits one through nine, with each list followed by some representative and some nonrepresentative digits. Ss were warned that some of the test items might be repeated within a set of trials. Ss were told to press the key for their dominant hand when representatives of the digit lists appeared and to press the key for the other hand when nonrepresentatives of the digit lists appeared. Qiick and accurate responses were requested of the Ss.

Positive sets were transmitted by $\mathrm{E}$ in two ways, depending on the ruleboundedness of the set. NR sets were transmitted as follows (for a set of Size 4): "The set contains 1, 5, 6, and 8 ... $1,5,6$, and 8." $\mathrm{R}$ sets were transmitted as follows (for a set of Size 4): "The set contains the multiples of two . . 2, 4, 6, 8."

Fifteen test trials followed presentation of the positive set. Each trial took about $30 \mathrm{sec}$. A 2-min rest period was allowed between each set of trials.

\section{RESULTS}

Mean CRTs for all conditions are represented in Fig. 1. In the NR condition, slope of the fitted line was $41.30 \mathrm{msec}$ and the zero intercept was $357.74 \mathrm{msec}$. 
Linear regression accounted for $99 \%$ of the variance of overall mean response latencies in the NR condition. Slope of the fitted line in the $\mathrm{R}$ condition was $9.70 \mathrm{msec}$ and the zero intercept was $424.38 \mathrm{msec}$. Linear regression accounted for only $72 \%$ of the variance of overall response latencies in the $\mathrm{R}$ condition.

To offset individual differences in response latency, baselines for each $S$, obtained in the first part of the experiment, were subtracted from each S's mean CRT in each of the six experimental conditions. The $t$ of correlated means between corrected CRTs in the R and NR condition was significant when the memory set size was four $(t=2.96, p<.02)$, but not significant when the memory set size was three $(t=1.21)$ or two $(t=$ $.05)$.

R-NR effects, as measured with analysis of variance, were not significant, $F(1,84)<1.00$. Memory set size effects were also not significant, $F(2,84)<1.00$. But interaction effects were significant, $F(2,84)=3.48$, $\mathrm{p}<.05$.

Differences between positive and negative choice responses were not affected by memory set size or ruleboundedness. Negative CRTs were always slightly longer than positive CRTs. Comparison of the ratios of mean positive CRT/mean negative CRT for the $R$ and $N R$ conditions yielded $t$ values of $-0.12, .25$, and -0.12 for memory set sizes of two, three, and four, respectively. The generalized $\mathrm{Z}$ value for proportional differences was -0.04 .

Stimulus repetition had no significant effect on CRTs.

Errors were committed on less than $1 \%$ of the trials for all Ss. For this reason, only correct responses were included in the present data analysis.

\section{DISCUSSION}

The results contravene predictions of the stochastic self-terminating search model. Rule use contributed to the reduction of CRTs in all memory set size conditions. Although serial processing characterized Ss' scanning routines in the NR condition, serial processing may not have been used in the $\mathrm{R}$ condition. Prolonged practice with the character classification procedure was not a prerequisite for Ss to perform as if they had had prolonged practice with unchunked sets (Kristofferson, 1972b).

Although the results do not provide unequivocal support for the corollary mentioned earlier, where it was proposed that serial and parallel processing are distinguished by graded, chunk-dependent factors, it may be worthwhile to consider this idea now. First it must be determined whether chunking promotes parallel processing. From data such as Neisser and Beller's (1965), Neisser and Stoper's (1965), and several others' (cf. Neisser, 1967), it is clear that this is so. The word apprehension effect is an excellent illustration of the extent to which chunking promotes parallel scanning. The second issue that must be considered is whether chunking can occur as an incremental process. Rock (1957) offered putative proof that learning (as tested with paired associates) is not incremental, but objections and qualifications by Williams (1961), Underwood, Rehula, and Keppel (1962), Battig (1962), and Postman (1963) pointed instead to a two-stage model of paired-associate learning consisting of a response acquisition and an association acquisition stage. Evidence that association acquisition is a gradual process in which stimulus components are accumulated through a series of all-or-none steps was provided by Bregman and Chambers (1966), Suppes and Ginsberg (1963), Bower and Theios (1964), and Restle (1964). Concerning incremental chunking directly, it is apparent that a hierarchical model of chunking can allow for chunk expansion; more elements can be subsumed in the chunk as the hierarchy is expanded (cf. Postman, 1972). Kristofferson's (1972b) use of nested positive sets probably took advantage of this fact. Similarly, it is interesting that the nested $R$ sets in the present experiment $(2,4,6,8$ and 4,8$)$ yielded lower CRTs than the extraneous $R$ set $(3,6,9)$.

Indirect evidence exists, therefore, to support the theory that serial and parallel scanning occupy a chunk-dependent continuum. More direct evidence can be found in the work of Miller, Bruner, and Postman (1954). Using strings of eight letters, Miller et al showed that identification thresholds for low-order approximations to English (e.g., IJHBWSTT) were higher than for high-order approximations to English (e.g., POKERSON). Order approximations were determined on the basis of natural frequencies of letter clusters sized one through four. Frequency effects became more pronounced as larger clusters were used, suggesting that faster identifications could be effected as more of the test string was chunked into a unitary whole. In all likelihood, faster identifications were due to an implementation of parallel scans rather than a speed-up of serial scans.

If serial and parallel processing do, in fact, form a continuum, then it is not clear where serial processing lets off and parallel processing begins. Yet there is a double-edged sword here: it is also not clear where parallel processing lets off and serial processing begins. Just as successive unitization of elements such as numerals and letters may lead to parallel scanning, the successive unitization of elements such as dots and lines may lead to the parallel processing of individual numerals or letters which at first may have been scanned serially. With this theoretical perspective, parallel and serial processing can be seen at interface. The search for perceptual or memorial units may comprise a search for the interface location in processing.

\section{REFERENCES}

Atkinson, R., Holmgren, J., \& Juola, J. Processing time as influenced by the number of elements in a visual display. Perception \& Psychophysics, 1969, 6, 321-326. 
3attig, W. Paired-associate learning under simultaneous repetition and nonrepetition conditions. Journal of Experimental Psychology, 1962, 64, 87-93.

3ertelson, P. S-R relationships and reaction times to new versus repeated signals in a serial task. Journal of Experimental Psychology, 1963, 65, 478-484.

3ertelson, P. Serial choice reaction-time as a function of response versus signal-and-response repetition. Nature, 1965 , 206, 217-218.

3ertelson, P., \& Tisseyre, F. Choice reaction time as a function of stimulus versus response relative frequency of occurrence. Nature, 1966, 212, 1069-1070.

3iederman, I., \& Zachary, R. Stimulus versus response probability in choice reaction time. Perception \& Psychophysics, 1970, 7, 189-192.

3ower, G., \& Theios, J. A learning model for discrete performance levels. In R. Atkinson (Ed.), Studies in mathematical psychology. Stanford: Stanford University Press, 1964.

Bregman, A., \& Chambers, D. All-or-none learning of attributes. Journal of Experimental Psychology, 1966, 71, 785-793.

Briggs, G., \& Blaha, J. Memory retrieval and central comparison times in information processing. Journal of Experimental Psychology, 1969, 79, 395-402.

Jlifton, C. Must overlearned lists be scanned? Memory \& Cognition, 1973, 1, 121-123.

Dallett, K. Number of categories and category information in free recall. Journal of Experimental Psychology, 1964, 68, $1-12$.

DeRosa, D., \& Beckwith, M. Retrieval of information from organized memory sets. Psychonomic Science, 1971, 23, 177-179.

DeRosa, D., \& Morin, R. Recognition reaction time for digits in consecutive and nonconsecutive memorized sets. Journal of Experimental Psychology, 1970, 83, 472-479.

Egeth, H., Jonidas, J., \& Wall, S. Parallel processing of multielement displays. Cognitive Psychology, 1972, 3, 674-698.

Falmagne, J, Stochastic models for choice reaction time with applications to experimental results. Journal of Mathematical Psychology, 1965, 12, 77-124.

Falmagne, J., \& Theios, J. On attention and memory in reaction time experiments. Acta Psychologica, 1969, 30, 316-323.

Hawkins, H., Thomas, G., \& Drury, K. Perceptual versus response bias in discrete reaction time. Journal of Experimental Psychology, 1970, 84, 514-517.

Hyman, R. Stimulus information as a determinant of reaction time. Journal of Experimental Psychology, 1953, 45, 188-196.

Kristofferson, M. Effects of practice on character-classification performance. Canadian Journal of Psychology, 1972a, 26, 54-60.

Kristofferson, M. When item recognition and visual search functions are similar. Perception \& Psychophysics, 1972b, 12 , 379-384.

Krueger, L. Effect of stimulus probability on two-choice reaction time. Journal of Experimental Psychology, 1970, 84, 377-379.

Leonard, J. Choice reaction time experiments and information theory. In C. Cherry (Ed.), Information theory: Proceedings of the Fourth London Symposium. London: Butterworth, 1961.

Leonard, J., Newman, R., \& Carpenter, A. On the handling of heavy bias in a self-paced task. Quarterly Journal of Experimental Psychology, 1966, 18, 130-141.

Marcel, A. Some constraints on sequential and parallel processing and the limits of attention. Acta Psychologica, 1970, 33, 77-92.

Miller, G., Bruner, J., \& Postman, L. Familiarity of letter sequences and tachistoscopic identification. Journal of General Psychology, 1954, 50, 129-139.

Morin, R., DeRosa, D., \& Stultz, V. Recognition memory and reaction time. Acta Psychologica, 1967, 27, 298-305.

Morin, R., Konick, A., Troxell, N., \& McPherson, S. Information and reaction time for "naming" responses. Journal of Experimental Psychology, 1965, 70, 309-314.

Mowbray, G., \& Rhoades, M. On the reduction of choice reaction times with practice. Quarterly Journal of Experimental Psychology, 1959, 11, 16-23.

Neisser, U. Decision-time without reaction-time: Experiments in visual scanning. American Journal of Psychology, 1963, 76, 376-385.

Neisser, U. Cognitive psychology. New York: Appleton-Century-Crofts, 1967.

Neisser, U., \& Beller, H. Searching through word lists. British Journal of Psychology, 1965, 56, 349-358.

Neisser, U., Novick, R., \& Lazar, R. Searching for ten targets simultaneously. Perceptual \& Motor Skills, 1963, 17, 955-961.

Neisser, U., \& Stoper, A. Redirecting the search process. British Journal of Psychology, 1965, 56, 359-368.

Orenstein, H. Reaction time as a function of perceptual bias, response bias, and stimulus discriminability. Journal of Experimental Psychology, 1970, 86, 38-42.

Postman, L. One-trial learning. In C. Cofer and B. Musgrave (Eds.), Verbal behavior and learning: Problems and processes. New York: McGraw-Hill, 1963.

Postman, L. A pragmatic view of organization theory. In E. Tulving and W. Donaldson (Eds.), Organization of memory. New York: Academic Press, 1972.

Reitman, J. Mechanisms of forgetting in short-term memory. Cognitive Psychology, 1971, 2, 185-195.

Remington, R. Analysis of sequential effects in choice reaction times. Journal of Experimental Psychology, 1969, 82, 250-257.

Restle, F. Sources of difficulty in learning paired-associates. In R. Atkinson (Ed.), Studies in mathematical psychology. Stanford: Stanford University Press, 1964.

Rock, I. The role of repetition in associative learning. American Journal of Psychology, 1957, 70, 186-193.

Schvaneveldt, R., \& Chase, W. Sequential effects in choice reaction time. Journal of Experimental Psychology, 1969, 80, $1-9$.

Snodgrass, J. Reaction times for comparisons of successively presented visual patterns: Evidence for serial self-terminating search. Perception \& Psychophysics, 1972, 12, 364-372.

Sternberg, S. High-speed scanning in human memory. Science, 1966, 153, 652-654.

Suppes, P., \& Ginsberg, R. A fundamental property of all-or-none models, binomial distribution of responses prior to conditioning, with application to concept formation in children. Psychological Review, 1963, 70, 139-161.

Theios, J., \& Smith, P. Can a two-state model account for two-choice reaction time data? Psychological Review, 1972, $79,172-177$.

Theios, J., Smith, P., Haviland, S., Traupmann, J., \& Moy, M. Memory scanning as a serial self-terminating process. Journal of Experimental Psychology, 1973, 97, 323-336.

Travers, J. The effects of forced serial processing on identification of words and random letter strings. Cognitive Psychology, in press.

Tulving, E. Subjective organization in free recall of unrelated words. Psychological Review, 1962, 69, 344-354.

Tulving, E. Subjective organization and effects of repetition in multitrial free-recall learning. Journal of Verbal Learning \& Verbal Behavior, 1966, 5, 193-197.

Underwood, B., Rehula, R., \& Keppel, G. Item selection in paired-associate learning. American Journal of Psychology, 1962, 75, 353-371. 
Wallace, W., \& Calderone, R. Implicit responses in incidental learning. Journal of Verbal Learning \& Verbal Behavior, 1969 , $8,136-142$.

Wattenbarger, B. Speed and accuracy set in visual search performance. Paper presented at the meeting of the Midwestern Psychological Association, Chicago, 1968.

Wattenbarger, B., \& Pachella, R. The effect of memory load on reaction time in character classification. Perception \& Psychophysics, 1972, 12, 100-102.
Williams, J. A selection artifact in Rock's study of the role of repetition. Journal of Experimental Psychology, 1961, 62, 627-628.

(Received for publication August 10, 1973; accepted August 26, 1973.) 